\title{
Monitoring dan Evaluasi Kinerja Karyawan menggunakan Algoritma Simple Additive Weighting dan Hungarian
}

\author{
Wawan Gunawan ${ }^{\mathrm{a}, 1, *}$ dan Muhammad Riski Firmansyaha, ${ }^{\mathrm{a}, 2}$ \\ ${ }^{a}$ Universitas Mercu Buana, Jl. Meruya Selatan No.1, Kembangan, Jakarta Barat 11650, Indonesia. \\ ${ }^{1}$ wawan.gunawan@mercubuana.ac.id; ${ }^{2} 41515120146 @$ student.mercubuana.ac.id; \\ *corresponding author
}

\section{INFORMASI ARTIKEL ABSTRAK}

\begin{tabular}{lll}
\hline Diterima & : 09 Februari 2020 & Monitoring dan evaluasi kinerja karyawan PT Akulaku Silvrr Indonesia \\
Diulas & $: 18$ Februari 2020 & masih menggunakan aplikasi Microsoft excel online, yang memiliki \\
Direvisi $:$ 14 Agustus 2020 & beberapa kelemahan, yang menjadi kendala dalam melakukan monitoring \\
Diterbitkan $: 27$ Agustus 2020 & adalah tidak dapat memberikan perintah pekerjaan secara spesifik dan tidak \\
& dapat memberikan informasi due date, sedangkan dalam penentuan \\
Kata Kunci: & pemberian kenaikan gaji dan tunjangan karyawan dilakukan secara acak \\
SAW & dan hanya berdasarkan pendidikan terakhir. Untuk membantu keberhasilan \\
Hungarian & perusahaan dalam mencapai tujuannya, dibutuhkan suatu sistem yang dapat \\
Monitoring & membantu dalam mengambil sebuah keputusan dalam skala besar maupun \\
Evaluasi & kecil. Penggunaan metode Simple Additive Weighting (SAW) dapat \\
Helpdesk & digunakan untuk menentukan kenaikan gaji dan pemberian insentif secara \\
& tepat dan akurat berdasarkan kriteria yang ditentukan, sedangkan metode \\
& Hungarian digunakan untuk menentukan siapa yang akan mengerjakan \\
& pekerjaan dengan tingkatan yang sulit, mudah dan juga sedang. Sehingga \\
& didapatkan pemeringkatan untuk kenaikan gaji bagi tim support.
\end{tabular}

Keywords:

SAW

Hungarian

Monitoring

Evaluation

Helpdesk

\begin{abstract}
Monitoring and evaluating the performance of employees of PT Akulaku Silvrr Indonesia still uses the Microsoft Excel online application, which has several weaknesses, the obstacles in monitoring are not being able to give specific work orders and not being able to provide due date information, while in determining the provision of salary increases and employee benefits are randomized and only based on recent education. To help the company's success in achieving its goals, we need a system that can help make decisions on a large or small scale. The use of the Simple Additive Weighting (SAW) method can be used to determine salary increases and incentives appropriately and accurately based on the specified criteria, while the Hungarian method is used to determine who will do the job with a difficult, easy and moderate level. So that the ranking for salary increases for the support team is Andi Ansyah, Hangga Bagus, Chikal Aviv and Ray Awaludin. The determination of the next assignment can be determined that Andi Ansyah can do easy and difficult jobs, Hangga Bagus can do easy and medium jobs, Chikal Aviv can do medium and difficult jobs. Meanwhile, Ray Awaludin did not have the highest score for every job, so he needed to be given training who will do the job with a difficult, easy and moderate level. So that the ranking for salary increases for the support team.
\end{abstract}

This is an open access article under the CC-BY-SA license.

\section{Pendahuluan}

Menghadapi arus globalisasi dan revolusi industri 4.0, sumber daya manusia (SDM) memegang peranan yang sangat dominan dalam aktivitas atau kegiatan perusahaan. Berhasil atau tidaknya perusahaan dalam mencapai tujuan yang ditetapkan, sangat tergantung pada kemampuan sumber daya manusianya (karyawan) dalam menjalankan tugas-tugas yang diberikan kepadanya [1]. Perusahaan perlu memotivasi dengan memberikan pelatihan untuk mengembangkan sumber daya manusia sehingga karyawan memiliki 
produktivitas yang tinggi dan juga mendorong perilaku kerja yang baik[2]. Selain itu perusahaan perlu memberikan suatu apresiasi kepada karyawannya[3] dapat berupa insentif dan juga kenaikan gaji[4] agar dapat mendorong kemajuan bagi perusahaan.

Saat ini untuk menentukan karyawan mana saja yang masuk dalam kriteria kenaikan gaji dan tunjangan karyawan di PT Akulaku Silvrr masih menggunakan perhitungan manual sehingga hasil yang diperoleh kurang begitu akurat, karena pemilihan dilakukan secara acak dan hanya berdasarkan pendidikan terakhir. Selain itu dalam menentukan kenaikan gaji dan tunjangan karyawan memiliki banyak kendala atau masalah yang harus dihadapi antara lain efisiensi waktu, banyak perbandingan variabel yang diuji, pengambilan keputusan apakah karyawan tersebut berhak naik atau tidak gajinya dan banyaknya berkas karyawan yang diolah[5][6].

Oleh karena itu untuk membantu keberhasilan perusahaan dalam mencapai tujuannya, dibutuhkan suatu sistem yang dapat membantu dalam mengambil sebuah keputusan dalam skala besar maupun kecil. Salah satunya adalah dengan dikembangkan sistem yang dapat membantu untuk melakukan monitoring [7] dan evaluasi. Sistem monitoring dan evaluasi yang dikembangkan memiliki beberapa alternatif, kriteria dan bobot yang dapat digunakan untuk menentukan suatu solusi terbaik [1]. Penerapan sistem monitoring dan evaluasi ini menggunakan metode Hungarian dan metode Simple Additive Weighting (SAW) yang nantinya dapat digunakan dalam penentuan kenaikan gaji karyawan dan juga pemberian insentif.

Metode SAW digunakan untuk implementasi sistem penilaian kinerja karyawan dan dapat digunakan oleh LPM Universitas Muhammadiyah Purwokerto[8], selain itu algoritma SAW juga telah digunakan dalam membantu pimpinan dalam memberikan informasi tentang penilaian prestasi kerja karyawan yang sesuai dengan keinginannya, dengan menggunakan metode SAW, menghasilkan alternatif yang sama dengan perhitungan yang dilakukan secara manual[3]. Metode Hungarian dapat digunakan untuk memberikan penugasan kepada karyawan dalam mengerjakan satu jenis pakaian dalam satu minggu, sehingga dapat mengoptimalkan jumlah baju yang dapat diselesaikan[9].

Untuk mendapatkan karyawan yang memenuhi kriteria yang tepat [6], maka dalam penelitian ini kami menentukan kriteria-kriteria penilaian terlebih dahulu. Setiap kriteria ini memiliki bobot masing-masing yang nantinya diolah dengan metode Simple Additive Weighting (SAW) untuk dapat menghasilkan penilaian karyawan berdasarkan tingkatan pekerjaan yang dilakukan. Selain menggunakan metode SAW, kami juga menggunakan metode Hungarian yang akan digunakan untuk menentukan siapa yang akan mengerjakan pekerjaan dengan tingkatan yang sulit, mudah dan juga dengan tingkat sedang sehingga didapatkan hasil dalam penentuan kenaikan gaji karyawan.

\section{Metode}

\section{A. Algortima Hungarian}

Model Penugasan (Assigment) pada awalnya dikenal sebagai Hungarian Method. Istilah ini diberikan untuk mengabadikan D. Konig, ahli matematika asal Hungaria yang pertama kali mengembangkan model ini [9]. Thomas J. Kakiay (2008) menyatakan bahwa masalah penugasan adalah alokasi dari banyak pekerjaan atau individu pekerja yang dinyatakan dengan $(m)$ untuk mengerjakan pekerjaan atau mesin dengan unit atau biaya yang sudah ditentukan [9]. Algoritma Hungarian ini dapat digunakan untuk menyelesaikan masalah penugasan secara dinamis dengan benar, hal ini sudah dibuktikan baik secara teori dan juga berdasarkan implementasi[10].

Metode penugasan digunakan untuk memaksimalkan keuntungan dalam suatu perusahaan. Beberapa hal yang harus diketahui dalam menyelesaikan masalah penugasan yaitu: jumlah pekerja $(m)$, jumlah pekerjaan yang akan diselesaikan $(n)$, penugasan pekerja pada suatu pekerjaan $\left(X_{i j}\right)$, parameter alokasi penugasan $\left(C_{i j}\right)$. Secara umum masalah penugasan dapat ditulis dengan rumus (1).

Maksimumkan $Z=$

$$
\sum_{i=1}^{m} \sum_{\mathrm{j}=1}^{\mathrm{n}} C_{i j} X_{i j}
$$

Dengan kendala sesuai persamaan (2):

$$
\begin{aligned}
& \sum_{i=1}^{m} i j=1 ; i=1,2, \ldots, m \\
& \sum_{i=1}^{n} i j=1 ; i=1,2, \ldots, n
\end{aligned}
$$




\section{B. Algortima Simple Additive Weighting (SAW)}

Menurut Kusumadewi, metode SAW sering juga dikenal istilah metode penjumlahan terbobot. Konsep dasar metode SAW adalah mencari penjumlahan terbobot dari rating kinerja pada setiap alternatif pada semua atribut[11]. Metode SAW membutuhkan proses normalisasi matriks keputusan (X) ke suatu skala yang dapat diperbandingkan dengan semua rating alternatif yang ada. Metode ini merupakan metode yang paling dikenal dan paling banyak digunakan orang dalam mengatasi situasi Multiple Attribute Decision Making (MADM). Metode ini mengharuskan pembuat keputusan menentukan bobot lagi untuk setiap atribut. Skor total untuk sebuah alternatif diperoleh dengan menjumlahkan seluruh perkalian antara rating (yang dapat dibandingkan lintas atribut) dan bobot tiap atribut. Rating tiap atribut haruslah bebas dimensi yang artinya telah melewati normalisasi terlebih dahulu [12].

Metode SAW mengenal adanya 2 (dua) atribut yaitu kriteria keuntungan (benefit) dan kriteria biaya $($ Cost $)$. Perbedaan mendasar dari kedua kriteria ini adalah dalam pemilihan kriteria ketika mengambil keputusan [13]. Adapun langkah-langkah penyelesaian dalam menggunaknnya adalah:

a. Menentukan Alternatif, yaitu Menentukan kriteria yang akan dijadikan acuan dalam pengambilan keputusan yaitu $\mathrm{C}_{\mathrm{j}}$.

b. Memberikan nilai rating kecocokan setiap alternatif pada setiap kriteria Menentukan bobot preferensi atau tingkat kepentingan (W) setiap kriteria dapat dilihat pada persamaan (3).

$$
\mathrm{W}=\left[\begin{array}{lllll}
W_{1} & W_{2} & W_{3} & \cdots & W_{j}
\end{array}\right]
$$

c. Membuat tabel rating kecocokan dari setiap alternatif pada setiap kriteria.

d. Membuat matrik keputusan yang dibentuk dari tabel rating kecocokan dari setiap alternatif pada setiap kriteria dapat dilihat pada persamaan (4). Nilai setiap alternatif $\left(\mathrm{A}_{\mathrm{i}}\right)$ pada setiap kriteria $\left(\mathrm{C}_{\mathrm{j}}\right)$ yang sudah ditentukan, di mana $i=1,2, \ldots, m$ dan $j=1,2, \ldots, n$.

$$
X=\left[\begin{array}{ccccc}
x_{11} & x_{12} & x_{13} & \ldots & x_{1 n} \\
x_{21} & x_{22} & x_{23} & \ldots & x_{2 n} \\
x_{31} & x_{32} & x_{33} & \ldots & x_{3 n} \\
\ldots & \ldots & \ldots & \ldots & \ldots \\
x_{m 1} & x_{m 2} & x_{m 3} & \ldots & x_{m n}
\end{array}\right]
$$

e. Melakukan normalisasi matrik keputusan dengan cara menghitung nilai rating kinerja ternormalisasi $\left(\mathrm{r}_{\mathrm{ij}}\right)$ dari alternatif $A_{i}$ pada kriteria $C_{j}$ lihat persamaan (5) dan (6).

$$
\begin{aligned}
& r_{i j}=\frac{X_{i j}}{\operatorname{Max}_{i} X_{i j}} \text { jika } \mathrm{j} \text { adalah atribut keuntungan (benefit) } \\
& r_{i j}=\frac{\operatorname{Min}_{i} X_{i j}}{X_{i j}} \text { jika j adalah atribut biaya }(\text { cost })
\end{aligned}
$$

Keterangan:

1. Dikatakan kriteria keuntungan apabila xij memberikan keuntungan bagi pengambil keputusan, sebaliknya kriteria biaya apabila xij menimbulkan biaya bagi pengambil keputusan.

2. Apabila berupa kriteria keuntungan maka nilai $\mathrm{x}_{\mathrm{ij}}$ dibagi dengan Maxi $\left(\mathrm{x}_{\mathrm{ij}}\right)$ dari setiap kolom, sedangkan kriteria biaya, nilai $\operatorname{Min}_{\mathrm{i}}\left(\mathrm{x}_{\mathrm{ij}}\right)$ dari setiap kolom dibagi dengan $\mathrm{xij}$.

f. Hasil dari rating kriteria ternormalisasi $\left(\mathrm{r}_{\mathrm{ij}}\right)$ membentuk matrik ternormalisasi (R) lihat persamaan (7)

$$
R=\left[\begin{array}{ccccc}
r_{11} & r_{12} & r_{13} & \ldots & r_{1 n} \\
r_{21} & r_{22} & r_{23} & \ldots & r_{2 n} \\
r_{31} & r_{32} & r_{33} & \ldots & r_{3 n} \\
\ldots & \ldots & \ldots & \ldots & \ldots \\
r_{m 1} & r_{m 2} & r_{m 3} & \ldots & r_{m n}
\end{array}\right]
$$

g. Hasil akhir nilai preferensi $\left(\mathrm{V}_{\mathrm{i}}\right)$ diperoleh dari penjumlahan dari perkalian elemen baris matrik ternormalisasi $(\mathrm{R})$ dengan bobot preferensi (W) yang bersesuaian elemen kolom matrik (W) lihat persamaan (8) 


$$
V_{i}=\sum_{j=1}^{n} w_{j} r_{i j}
$$

Hasil perhitungan nilai $\mathrm{V}_{\mathrm{i}}$ yang paling besar mengindikasikan bahwa alternatif Ai merupakan alternatif yang terbaik.

Metodologi penelitian menguraikan seluruh kegiatan yang dilakukan dalam pembangunan atau perancangan aplikasi selama penelitian berlangsung. Adapun langkah-langkah seperti flowchart dilakukan pada saat penilitian seperti pada Gambar 1 .

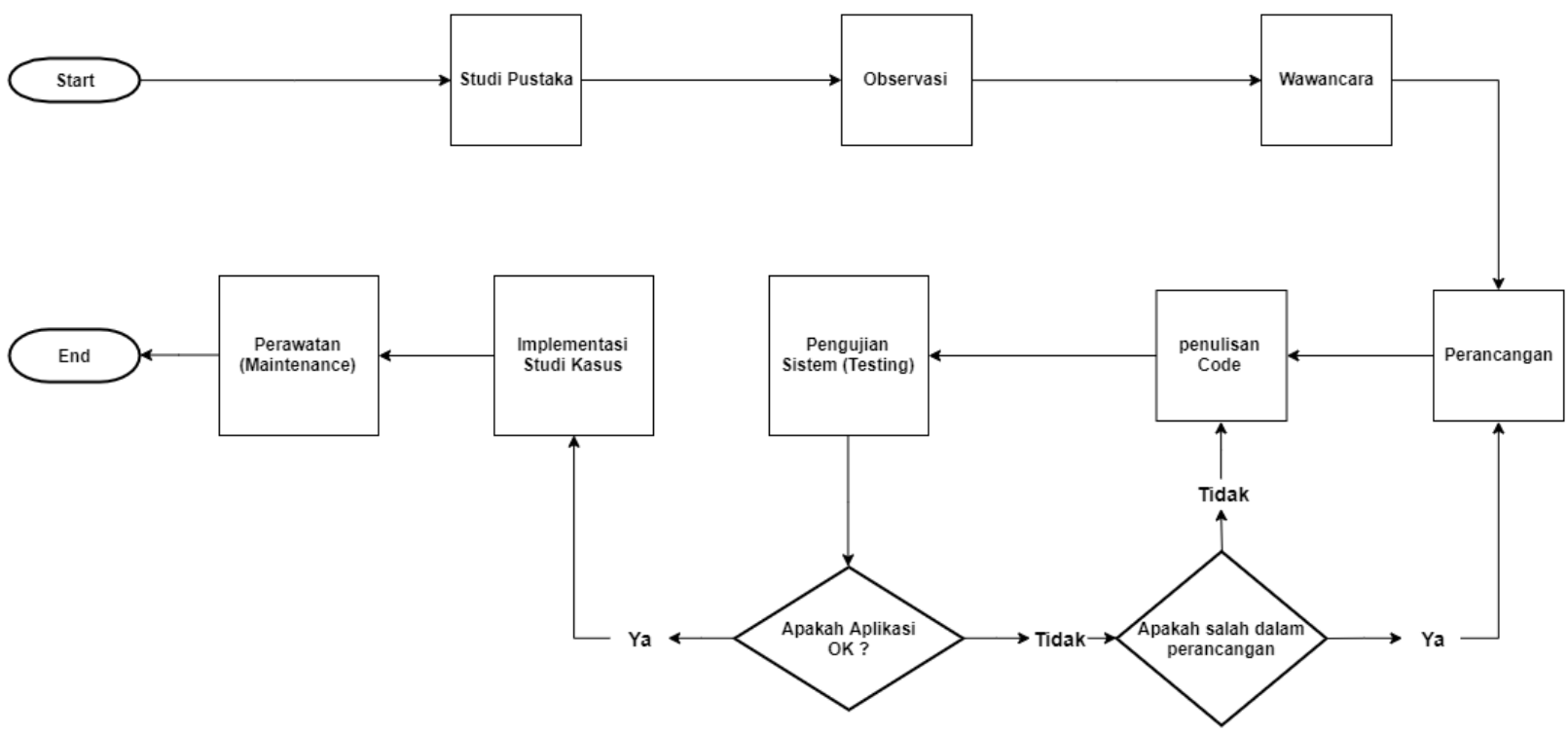

Gambar 1. Flowchart

A. Analisa Sistem

Menganalisa data- data yang dibutuhkan sebelum memulai perancangan aplikasi.

1. Studi Pustaka

Mempelajari algoritma Hungarian dan SAW dan cara penggunaannya, serta mempelajari pembuatan sistem aplikasi monitoring dan evaluasi.

2. Observasi

Mengumpulkan data-data yang bersesuaian dengan penyelesaian algoritma yang digunakan dan pembuatan sistem aplikasi.

3. Wawancara

Mewawancarai pegawai dan manager yang ada pada perusahan Akulaku, guna untuk megumpulkan kebutuhan, keperluan dalam pelaksanaan pekerjaan yang akan diimplementasi pada aplikasi.

\section{Hasil dan Pembahasan}

\section{A. Perancangan Penilaian Karyawan}

Agar penilaian program dapat berjalan dengan efisien, penilaian karyawan pada perancangan penilaian ini menggunakan tiga ketentuan poin penilaian yaitu, poin tiket, rating tiket, dan absen karyawan. Dari ke tiga ketentuan poin penilaian ini memiliki value-nya masing-masing yang ditampilkan pada Tabel 1 dengan dataset yang dipersiapkan untuk tiket dapat dilihat pada Tabel 2 dan untuk absensi dapat dilihat pada Tabel 3.

Tabel 1. Ketentuan Poin

\begin{tabular}{|c|c|c|c|c|}
\hline \multicolumn{5}{|c|}{ Ketentuan Poin } \\
\hline Tipe Tiket & Point & Rating & Absen & Point \\
\hline Sulit & 6 & & Masuk & 1 \\
\hline Sedang & 3 & & Sakit Dengan Surat & 1 \\
\hline Mudah & 1 & Rating yang & Cuti & 1 \\
\hline & & di gunakan 1-5 & Sakit Tanpa Surat & 0 \\
\hline & & & Ijin & 0 \\
\hline & & & Alpha & 0 \\
\hline
\end{tabular}


Tabel 2. Dataset Tiket

\begin{tabular}{ccccccc}
\hline $\begin{array}{c}\text { Kode } \\
\text { Tiket }\end{array}$ & $\begin{array}{c}\text { Sup- } \\
\text { port }\end{array}$ & $\begin{array}{c}\text { Tgl. } \\
\text { Mulai }\end{array}$ & $\begin{array}{c}\text { Tgl. } \\
\text { Akhir }\end{array}$ & Tipe & Stat & $\begin{array}{c}\text { Rat- } \\
\text { ing }\end{array}$ \\
\hline TK-00001 & 1 & $01 / 10 / 2019$ & $02 / 10 / 2019$ & 1 & 3 & 4 \\
\hline TK-00002 & 3 & $01 / 10 / 2019$ & $02 / 10 / 2019$ & 1 & 3 & 4 \\
\hline TK-00003 & 4 & $01 / 10 / 2019$ & $02 / 10 / 2019$ & 1 & 3 & 3 \\
\hline TK-00004 & 1 & $02 / 10 / 2019$ & $03 / 10 / 2019$ & 3 & 3 & 3 \\
\hline TK-00005 & 2 & $02 / 10 / 2019$ & $03 / 10 / 2019$ & 2 & 3 & 3 \\
\hline TK-00006 & 3 & $02 / 10 / 2019$ & $03 / 10 / 2019$ & 1 & 3 & 4 \\
\hline TK-00007 & 3 & $02 / 10 / 2019$ & $03 / 10 / 2019$ & 1 & 3 & 4 \\
\hline TK-00008 & 2 & $02 / 10 / 2019$ & $03 / 10 / 2019$ & 2 & 3 & 4 \\
\hline TK-00009 & 1 & $03 / 10 / 2019$ & $04 / 10 / 2019$ & 2 & 3 & 4 \\
\hline TK-00010 & 2 & $02 / 10 / 2019$ & $04 / 10 / 2019$ & 2 & 3 & 4 \\
\hline TK-00011 & 3 & $03 / 10 / 2019$ & $07 / 10 / 2019$ & 3 & 3 & 4 \\
\hline TK-00012 & 2 & $03 / 10 / 2019$ & $07 / 10 / 2019$ & 3 & 3 & 4 \\
\hline TK-00013 & 1 & $03 / 10 / 2019$ & $07 / 10 / 2019$ & 3 & 3 & 5 \\
\hline TK-00014 & 3 & $03 / 10 / 2019$ & $04 / 10 / 2019$ & 2 & 3 & 5 \\
\hline TK-00015 & 4 & $04 / 10 / 2019$ & $06 / 10 / 2019$ & 2 & 3 & 5 \\
\hline TK-00016 & 4 & $04 / 10 / 2019$ & $05 / 10 / 2019$ & 2 & 3 & 5 \\
\hline TK-00017 & 1 & $09 / 10 / 2019$ & $10 / 10 / 2019$ & 2 & 3 & 5 \\
\hline TK-00018 & 2 & $09 / 10 / 2019$ & $10 / 10 / 2019$ & 1 & 3 & 5 \\
\hline TK-00019 & 3 & $09 / 10 / 2019$ & $10 / 10 / 2019$ & 1 & 3 & 5 \\
\hline TK-00020 & 4 & $09 / 10 / 2019$ & $10 / 10 / 2019$ & 1 & 3 & 5 \\
\hline TK-00021 & 2 & $10 / 10 / 2019$ & $11 / 10 / 2019$ & 1 & 3 & 5 \\
\hline TK-00022 & 3 & $10 / 10 / 2019$ & $11 / 10 / 2019$ & 1 & 3 & 5 \\
\hline TK-00023 & 3 & $03 / 10 / 2019$ & $04 / 10 / 2019$ & 1 & 3 & 5 \\
\hline TK-00024 & 4 & $11 / 10 / 2019$ & $12 / 10 / 2019$ & 1 & 3 & 5 \\
\hline TK-00025 & 2 & $14 / 10 / 2019$ & $15 / 10 / 2019$ & 1 & 3 & 5 \\
\hline TK-00026 & 3 & $14 / 10 / 2019$ & $15 / 10 / 2019$ & 1 & 3 & 5 \\
\hline TK-00027 & 4 & $14 / 10 / 2019$ & $16 / 10 / 2019$ & 2 & 3 & 5 \\
\hline TK-00028 & 1 & $16 / 10 / 2019$ & $21 / 10 / 2019$ & 3 & 3 & 5 \\
\hline TK-00029 & 2 & $16 / 10 / 2019$ & $17 / 10 / 2019$ & 1 & 3 & 3 \\
\hline & & & & & & \\
\hline
\end{tabular}

\begin{tabular}{ccccccc}
\hline $\begin{array}{c}\text { Kode } \\
\text { Tiket }\end{array}$ & $\begin{array}{c}\text { Sup- } \\
\text { port }\end{array}$ & $\begin{array}{c}\text { Tgl. } \\
\text { Mulai }\end{array}$ & $\begin{array}{c}\text { Tgl. } \\
\text { Akhir }\end{array}$ & Tipe & Stat & $\begin{array}{c}\text { Rat- } \\
\text { ing }\end{array}$ \\
\hline TK-00030 & 3 & $16 / 10 / 2019$ & $22 / 10 / 2019$ & 3 & 3 & 3 \\
\hline TK-00031 & 4 & $16 / 10 / 2019$ & $17 / 10 / 2019$ & 1 & 3 & 3 \\
\hline TK-00032 & 2 & $16 / 10 / 2019$ & $19 / 10 / 2019$ & 2 & 3 & 4 \\
\hline TK-00033 & 2 & $17 / 10 / 2019$ & $21 / 10 / 2019$ & 2 & 3 & 5 \\
\hline TK-00034 & 1 & $21 / 10 / 2019$ & $23 / 10 / 2019$ & 2 & 3 & 5 \\
\hline TK-00035 & 3 & $21 / 10 / 2019$ & $24 / 10 / 2019$ & 2 & 3 & 4 \\
\hline TK-00036 & 2 & $22 / 10 / 2019$ & $23 / 10 / 2019$ & 2 & 3 & 4 \\
\hline TK-00037 & 4 & $22 / 10 / 2019$ & $24 / 10 / 2019$ & 2 & 3 & 5 \\
\hline TK-00038 & 1 & $22 / 10 / 2019$ & $24 / 10 / 2019$ & 2 & 3 & 5 \\
\hline TK-00039 & 3 & $23 / 10 / 2019$ & $28 / 10 / 2019$ & 2 & 3 & 5 \\
\hline TK-00040 & 2 & $23 / 10 / 2019$ & $28 / 10 / 2019$ & 2 & 3 & 5 \\
\hline TK-00041 & 4 & $23 / 10 / 2019$ & $28 / 10 / 2019$ & 2 & 3 & 5 \\
\hline TK-00042 & 1 & $24 / 10 / 2019$ & $28 / 10 / 2019$ & 2 & 3 & 5 \\
\hline TK-00043 & 2 & $25 / 10 / 2019$ & $28 / 10 / 2019$ & 2 & 3 & 5 \\
\hline TK-00044 & 4 & $25 / 10 / 2019$ & $28 / 10 / 2019$ & 2 & 3 & 5 \\
\hline TK-00045 & 1 & $01 / 10 / 2019$ & $02 / 10 / 2019$ & 2 & 3 & 5 \\
\hline TK-00046 & 3 & $28 / 10 / 2019$ & $31 / 10 / 2019$ & 2 & 3 & 3 \\
\hline TK-00047 & 2 & $02 / 10 / 2019$ & $03 / 10 / 2019$ & 1 & 3 & 4 \\
\hline TK-00048 & 4 & $29 / 10 / 2019$ & $30 / 10 / 2019$ & 1 & 3 & 4 \\
\hline TK-00049 & 2 & $29 / 10 / 2019$ & $30 / 10 / 2019$ & 1 & 3 & 5 \\
\hline TK-00050 & 4 & $29 / 10 / 2019$ & $30 / 10 / 2019$ & 1 & 3 & 5 \\
\hline TK-00051 & 1 & $30 / 10 / 2019$ & $31 / 10 / 2019$ & 1 & 3 & 4 \\
\hline TK-00052 & 2 & $30 / 10 / 2019$ & $31 / 10 / 2019$ & 1 & 3 & 5 \\
\hline TK-00053 & 3 & $30 / 10 / 2019$ & $31 / 10 / 2019$ & 1 & 3 & 4 \\
\hline TK-00054 & 4 & $30 / 10 / 2019$ & $31 / 10 / 2019$ & 1 & 3 & 3 \\
\hline TK-00055 & 1 & $30 / 10 / 2019$ & $31 / 10 / 2019$ & 1 & 3 & 4 \\
\hline TK-00056 & 3 & $30 / 10 / 2019$ & $31 / 10 / 2019$ & 1 & 3 & 4 \\
\hline TK-00057 & 2 & $31 / 10 / 2019$ & $04 / 11 / 2019$ & 2 & 3 & 4 \\
\hline TK-00058 & 4 & $31 / 10 / 2019$ & $04 / 11 / 2019$ & 2 & 3 & 4 \\
\hline
\end{tabular}

Tabel 3. Dataset Absensi

\begin{tabular}{ccc}
\hline $\begin{array}{c}\text { Tgl } \\
\text { Absen }\end{array}$ & $\begin{array}{c}\text { Sup- } \\
\text { port }\end{array}$ & $\begin{array}{c}\text { Status } \\
\text { Absen }\end{array}$ \\
\hline $01 / 10 / 2019$ & 1 & Masuk \\
\hline $01 / 10 / 2019$ & 2 & Izin \\
\hline $01 / 10 / 2019$ & 3 & Masuk \\
\hline $01 / 10 / 2019$ & 4 & Masuk \\
\hline $02 / 10 / 2019$ & 1 & Masuk \\
\hline $02 / 10 / 2019$ & 2 & Masuk \\
\hline $02 / 10 / 2019$ & 3 & Masuk \\
\hline $02 / 10 / 2019$ & 4 & Alpha \\
\hline $03 / 10 / 2019$ & 1 & Masuk \\
\hline $03 / 10 / 2019$ & 2 & Masuk \\
\hline $03 / 10 / 2019$ & 3 & Masuk \\
\hline $03 / 10 / 2019$ & 4 & Izin \\
\hline $04 / 10 / 2019$ & 1 & Masuk \\
\hline $04 / 10 / 2019$ & 2 & Masuk \\
\hline $04 / 10 / 2019$ & 3 & Masuk \\
\hline $04 / 10 / 2019$ & 4 & Masuk \\
\hline $07 / 10 / 2019$ & 1 & Masuk \\
\hline $07 / 10 / 2019$ & 2 & Masuk \\
\hline $07 / 10 / 2019$ & 3 & Masuk \\
\hline $07 / 10 / 2019$ & 4 & Masuk \\
\hline $08 / 10 / 2019$ & 1 & Masuk \\
\hline $08 / 10 / 2019$ & 2 & Masuk \\
\hline $08 / 10 / 2019$ & 3 & Masuk \\
\hline & &
\end{tabular}

\begin{tabular}{ccc}
\hline $\begin{array}{c}\text { Tgl } \\
\text { Absen }\end{array}$ & $\begin{array}{c}\text { Sup- } \\
\text { port }\end{array}$ & $\begin{array}{c}\text { Status } \\
\text { Absen }\end{array}$ \\
\hline $08 / 10 / 2019$ & 4 & Masuk \\
\hline $09 / 10 / 2019$ & 1 & Masuk \\
\hline $09 / 10 / 2019$ & 2 & Masuk \\
\hline $09 / 10 / 2019$ & 3 & Masuk \\
\hline $09 / 10 / 2019$ & 4 & Masuk \\
\hline $10 / 10 / 2019$ & 1 & Masuk \\
\hline $10 / 10 / 2019$ & 2 & Masuk \\
\hline $10 / 10 / 2019$ & 3 & Masuk \\
\hline $10 / 10 / 2019$ & 4 & Masuk \\
\hline $11 / 10 / 2019$ & 1 & Izin \\
\hline $11 / 10 / 2019$ & 2 & Masuk \\
\hline $11 / 10 / 2019$ & 3 & Masuk \\
\hline $11 / 10 / 2019$ & 4 & Masuk \\
\hline $14 / 10 / 2019$ & 1 & Izin \\
\hline $14 / 10 / 2019$ & 2 & Masuk \\
\hline $14 / 10 / 2019$ & 3 & Masuk \\
\hline $14 / 10 / 2019$ & 4 & Masuk \\
\hline $15 / 10 / 2019$ & 1 & Masuk \\
\hline $15 / 10 / 2019$ & 2 & Masuk \\
\hline $15 / 10 / 2019$ & 3 & Masuk \\
\hline $15 / 10 / 2019$ & 4 & Masuk \\
\hline $16 / 10 / 2019$ & 1 & Masuk \\
\hline $16 / 10 / 2019$ & 2 & Masuk \\
\hline & &
\end{tabular}

\begin{tabular}{ccc}
\hline $\begin{array}{c}\text { Tgl } \\
\text { Absen }\end{array}$ & $\begin{array}{c}\text { Sup- } \\
\text { port }\end{array}$ & $\begin{array}{c}\text { Status } \\
\text { Absen }\end{array}$ \\
\hline $16 / 10 / 2019$ & 3 & Masuk \\
\hline $16 / 10 / 2019$ & 4 & Masuk \\
\hline $17 / 10 / 2019$ & 1 & Masuk \\
\hline $17 / 10 / 2019$ & 2 & Masuk \\
\hline $17 / 10 / 2019$ & 3 & Masuk \\
\hline $17 / 10 / 2019$ & 4 & Masuk \\
\hline $18 / 10 / 2019$ & 1 & Masuk \\
\hline $18 / 10 / 2019$ & 2 & Masuk \\
\hline $18 / 10 / 2019$ & 3 & Masuk \\
\hline $18 / 10 / 2019$ & 4 & Masuk \\
\hline $21 / 10 / 2019$ & 1 & Masuk \\
\hline $21 / 10 / 2019$ & 2 & Masuk \\
\hline $21 / 10 / 2019$ & 3 & Masuk \\
\hline $21 / 10 / 2019$ & 4 & Masuk \\
\hline $22 / 10 / 2019$ & 1 & Masuk \\
\hline $22 / 10 / 2019$ & 2 & Masuk \\
\hline $22 / 10 / 2019$ & 3 & Masuk \\
\hline $22 / 10 / 2019$ & 4 & Izin \\
\hline $23 / 10 / 2019$ & 1 & Masuk \\
\hline $23 / 10 / 2019$ & 2 & Masuk \\
\hline $23 / 10 / 2019$ & 3 & Masuk \\
\hline $23 / 10 / 2019$ & 4 & Masuk \\
\hline $24 / 10 / 2019$ & 1 & Masuk \\
\hline & &
\end{tabular}

\begin{tabular}{ccc}
\hline $\begin{array}{c}\text { Tgl } \\
\text { Absen }\end{array}$ & $\begin{array}{c}\text { Sup- } \\
\text { port }\end{array}$ & Status Absen \\
\hline $24 / 10 / 2019$ & 2 & Masuk \\
\hline $24 / 10 / 2019$ & 3 & Masuk \\
\hline $24 / 10 / 2019$ & 4 & Masuk \\
\hline $25 / 10 / 2019$ & 1 & Sakit tanpa surat \\
\hline $25 / 10 / 2019$ & 2 & Masuk \\
\hline $25 / 10 / 2019$ & 3 & Masuk \\
\hline $25 / 10 / 2019$ & 4 & Masuk \\
\hline $28 / 10 / 2019$ & 1 & Masuk \\
\hline $28 / 10 / 2019$ & 2 & Masuk \\
\hline $28 / 10 / 2019$ & 3 & Masuk \\
\hline $28 / 10 / 2019$ & 4 & Masuk \\
\hline $29 / 10 / 2019$ & 1 & Masuk \\
\hline $29 / 10 / 2019$ & 2 & Masuk \\
\hline $29 / 10 / 2019$ & 3 & Masuk \\
\hline $29 / 10 / 2019$ & 4 & Masuk \\
\hline $30 / 10 / 2019$ & 1 & Masuk \\
\hline $30 / 10 / 2019$ & 2 & Masuk \\
\hline $30 / 10 / 2019$ & 3 & Masuk \\
\hline $30 / 10 / 2019$ & 4 & Masuk \\
\hline $31 / 10 / 2019$ & 1 & Masuk \\
\hline $31 / 10 / 2019$ & 2 & Masuk \\
\hline $31 / 10 / 2019$ & 3 & Masuk \\
\hline $31 / 10 / 2019$ & 4 & Masuk \\
\hline & & \\
\hline
\end{tabular}

Selanjutnya dari kriteria poin yang sudah ditentukan akan dikalkulasikan ke dalam algoritma Simple Additive Weighting (SAW). Masing-masing karyawan akan mendapatkan value yang berbeda. Pada algoritma SAW, tentunya wajib memiliki nilai kriteria tersendiri seperti yang dtampilkan pada Tabel 4.

Tabel 4. Bobot kriteria

\begin{tabular}{ccc}
\hline & Kriteria & \\
\hline Benefit & Benefit & Cost \\
\hline Tiket $(\mathrm{C} 1)$ & Absen $(\mathrm{C} 2)$ & Rating $(\mathrm{C} 3)$ \\
\hline 0.45 & 0.35 & 0.2 \\
\hline
\end{tabular}

Bersumber dari dataset pada Tabel 2 dan juga pada Tabel 3 dapat dibuat rekapitulasi dengan nilai alternatif seperti yang ditunjukan pada Tabel 5, dengan ketentutan seperti berikut ini: 
a. Pada kolom Tiket (C1), nilai yang didapat dihasilkan dari berapa banyak tim support menerima tiket dalam rentang waktu 1 bulan berdasarkan tingkat kesulitan yang bersumber dari tabel 2 kolom Tipe, selanjutnya dari tingkat kesulitan tersebut dirujuk pada Tabel 1 untuk menentukan poin berdasarkan tingkat kesulitan. Jika Tipe dari permintaan tersebut adalah Sulit (3) maka mendapat nilai 6, jika Sedang (2) maka mendapat nilai 3, dan jika Tipe permintaan tersebut adalah Mudah (1) maka mendapat nilai 1 .

Sebagai contoh untuk support "1" mendapatkan request tiket dengan Tipe Mudah (1) sebanyak 3 kali, tipe Sedang (2) sebanyak 6 kali dan tipe Sulit (3) sebanyak 3 kali, maka akan dihasilkan nilai sebanyak $(1 * 3)+(3 * 6)+(3 * 6)=39$ poin.

b. Pada kolom Absen (C2), nilai yang diapat dihasilkan dari dataset absensi yang ada pada tabel 3 dan dirujuk pada tabel 1 yaitu ketentuan poin. Jika pada tabel 3 kolom Status Absen berisi Masuk atau Sakit Dengan Surat atau Cuti maka mendapatkan nilai 1, selain itu nilai 0.

Sebagai contoh untuk support "1", isian pada kolom Status Absen dengan keterangan Masuk sebanyak 20 kali, Izin sebanyak 2 kali, dan Sakit Tanpa Surat sebanyak 1 kali.

c. Selanjutnya pada kolom Rating (C3), nilai yang didapat dihasilkan dari berapa banyak jumlah penilaian yang dilakukan oleh user terhadap Support pada kolom Rating di Tabel 2 dibandingkan dengan pemberian nilai maksimal atas permintaan yang telah diselesaikan.

Sebagai contoh untuk support "1", isian pada kolom Rating dengan nilai 3 sebanyak 1 kali, nilai 4 sebanyak 4 kali, dan nilai 5 sebanyak 7 kali. Dengan memperhatikan tabel 1 untuk kolom Rating akan diberikan penilaian minimal adalah 1 dan maksimal adalah 5, maka untuk penilaian support ini dapat dikalkulasikan dengan $(3 * 1)+(4 * 4)+(5 * 7) /(5 * 1)+(4 * 5)+(5 * 7)=54 / 60=0,9$.

Dari proses tersebut maka dihasilkan nilai alternatif seperti yang ditampilkan pada Tabel 5.

Tabel 5. Nilai alternatif

\begin{tabular}{cccc}
\hline \multirow{2}{*}{ No } & \multicolumn{4}{c}{ Kriteria } \\
\cline { 2 - 4 } & Tiket $(\mathrm{C} 1)$ & Absen $(\mathrm{C} 2)$ & Rating $(\mathrm{C} 3)$ \\
\hline 1 & 39 & 20 & 0.9 \\
\hline 2 & 40 & 22 & 0.870588235 \\
\hline 3 & 33 & 23 & 0.8533333333 \\
\hline 4 & 28 & 20 & 0.885714286 \\
\hline
\end{tabular}

Selanjutnya setelah mendapatkan nilai alternatif tersebut dilakukan proses normalisasi dengan menggunakan persamaan 5 untuk kriteria yang bersifat benafit dan persamaan 6 untuk kriteria yang bersifat cost. Nilai maksimal pada kriteria Tiket adalah 40, dan nilai maksimal pada kriteria Absen adalah 23. Sedangkan pada kriteria Rating nilai minimalnya adalah 0,853333333 . Maka dapat dihasilkan nilai matriks normalisasi seperti pada Tabel 6 .

Tabel 6. Nilai matriks normalisasi

\begin{tabular}{cccc}
\hline \multirow{2}{*}{ No } & \multicolumn{4}{c}{ Kriteria } \\
\cline { 2 - 4 } & Tiket $(\mathrm{C} 1)$ & Absen $(\mathrm{C} 2)$ & Rating $(\mathrm{C} 3)$ \\
\hline 1 & 0.975 & 0.869565217 & 0.948148148 \\
\hline 2 & 1 & 0.956521739 & 0.98018018 \\
\hline 3 & 0.825 & 1 & 1 \\
\hline 4 & 0.7 & 0.869565217 & 0.96344086 \\
\hline
\end{tabular}

Selanjutunya setelah itu dilakukan proses pemeringkatan sesuai dengan persamaan 8 sehingga dihasilkan perhitungan sebagai berikut

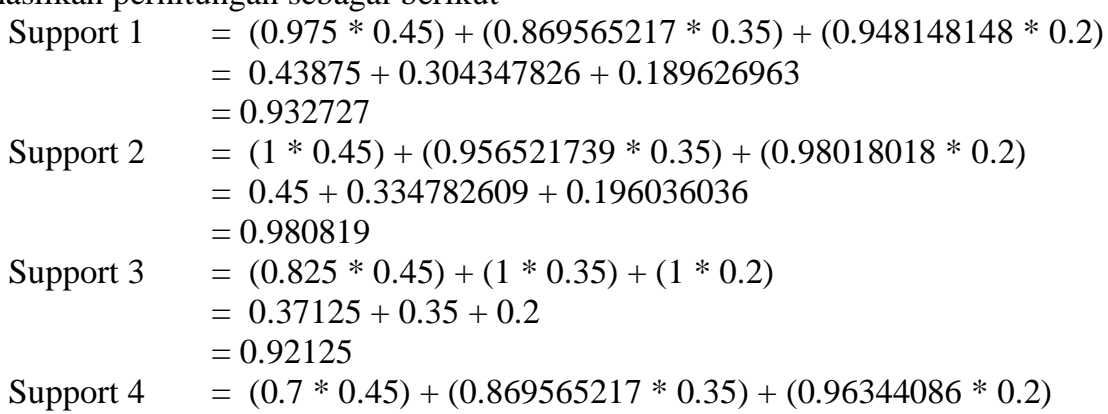




$$
\begin{aligned}
& =0.315+0.304347826+0.192688172 \\
& =0.812036
\end{aligned}
$$

Hasil dari perhitungan tersebut maka dihasilkan nilai akhir seperti pada Tabel 7.

Tabel 7. Nilai akhir

\begin{tabular}{cc}
\hline Alternatif & Nilai \\
\hline 1 & 0.932727 \\
\hline 2 & 0.980819 \\
\hline 3 & 0.92125 \\
\hline 4 & 0.812036 \\
\hline
\end{tabular}

Dari hasil perhitungan tersebut maka bisa dipastikan nilai tertinggi adalah nilai yang direkomendasikan untuk penilaian karyawan dalam pemenuhan KPI, dengan hasil akhir seperti ditampilkan pada Tabel 8.

Tabel 8. Perangkingan alternatif

\begin{tabular}{ccccc}
\hline No & Kode Alternatif & Nama Alternatif & Total Nilai & Perangkingan \\
\hline 1 & 1 & Hangga Bagus & 0.932727 & 2 \\
\hline 2 & 2 & Andi Ansyah & 0.980819 & 1 \\
\hline 3 & 3 & Chikal Aviv & 0.92125 & 3 \\
\hline 4 & 4 & Ray Awaludin & 0.812036 & 4 \\
\hline
\end{tabular}

\section{B. Perancangan Alokasi Pekerjaan}

Untuk dapat mengalokasikan pekerjaan dengan mudah dan akurat, pada alokasi pekerjaan ini di buatlah sistem yang menggunakan metode Hungarian. Metode ini membutuhkan ketentuan nilai yang di dapat dari type tiket dan jumlah hari pengerjaan dari masing-masing target tipe tiket yang sudah di kerjakan oleh support. Lalu value ini nanti nya akan di kalkulasikan yang dapat menghasilkan nilai tertinggi dan terendah dari masing-masing tipe tiket yang di kerjakan. Dan nilai ini lah yang akan menentukan alokasi tipe pekerjaan terhadap karyawan support.

Untuk implementasi alokasi perkerjaan dari berbagai type pekerjaan yang telah di-request oleh user. Manager akan menghitung total waktu yang sudah di kerjaan dari masing-masing karyawan user dengan menggunakan metode Hungarian. Identifikasi dan penyerdahaan masalah ini mengunakan perhitungan total hari pengerjaan dari tipe tiket yang sudah di kerjakan, Seperti pada Tabel 9:

Tabel 9. Identifikasi dan penyederhanaan

\begin{tabular}{ccccc}
\hline \multicolumn{1}{l}{ Type Pekerjaan } & Hangga Bagus & Andi Ansyah & Chikal Aviv & \multicolumn{2}{c}{ Ray Awaludin } \\
\hline Mudah & 3 Hari & 7 Hari & 9 hari & 7 hari \\
\hline Sedang & 12 Hari & 18 Hari & 10 Hari & 12 Hari \\
\hline Sulit & 11 Hari & 3 Hari & 10 Hari & 0 hari \\
\hline Jumlah Hari pekerjaan & 30 Hari & 40 Hari & 27 Hari & 28 Hari \\
\hline
\end{tabular}

Dari Tabel 9, lalu cari nilai terbesar untuk setiap baris, dan kemudian gunakan nilai tersebut untuk mengurangi nilai hari pada baris yang sama. Lalu nila jumlah hari pekerjaan di buat menjadi 0. Jumlah hari pekerjaan ini adalah jumlah hari dari tiket yang dikerjakan jika tiket yang dikerjakan benar-benar tepat sesuai dengan hari yang sudah di tentukan yang terlihat pada Tabel 10.

Tabel 10. Nilai Terbesar

\begin{tabular}{cccccc}
\hline Type Pekerjaan & Hangga Bagus & Andi Ansyah & Chikal Aviv & Ray Awaludin \\
\hline Mudah & 3 & 7 & 9 & 7 \\
\hline Sedang & 12 & 18 & 10 & 12 \\
\hline Sulit & 11 & 3 & 10 & 0 \\
\hline Jumlah Hari pekerjaan & 0 & 0 & 0 & 0 \\
\hline
\end{tabular}


Setelah menentukan nilai terbesar pada masing-masing baris dan melakukan perubahan pada baris jumlah hari pekerjaan, selanjutnya lakukan pengurangan dari nilai terbesar terhadap baris yang sama, sehingga hasilnya dapat dilihat pada Tabel 11.

Tabel 11. Pengubahan dan Pengurangan Nilai

\begin{tabular}{ccccc}
\hline Type Pekerjaan & Hangga Bagus & Andi Ansyah & Chikal Aviv & Ray Awaludin \\
\hline Mudah & 6 & 2 & 0 & 2 \\
\hline Sedang & 6 & 0 & 8 & 6 \\
\hline Sulit & 0 & 8 & 1 & kosong \\
\hline Jumlah Hari pekerjaan & $\mathrm{X}$ & $\mathrm{X}$ & $\mathrm{X}$ & 0 \\
\hline
\end{tabular}

Dari nilai hasil yang sudah di tentukan di atas. Bahwa nilai Ray Awaludin tidak memiliki nilai tertinggi dari semua tipe pekerjaan, tipe sedang dan sulit untuk chikal, lalu mudah dan sulit untuk Andi, dan yang terkhir mudah dan sedang untuk Hangga. Dari semua nilai ini, masing-masing karyawan yang masih memiliki nilai di dalam tabel masih dapat di alokasi pekerjaannya sesuai dengan tipe nya.

\section{Pemodelan Data}

Relasi tabel merupakan suatu model untuk menjelaskan hubungan antar data dalam basis data berdasarkan objek-objek dasar data yang mempunyai hubungan antar relasi [15]. Relasi tabel dimodelkan pada Gambar 3.

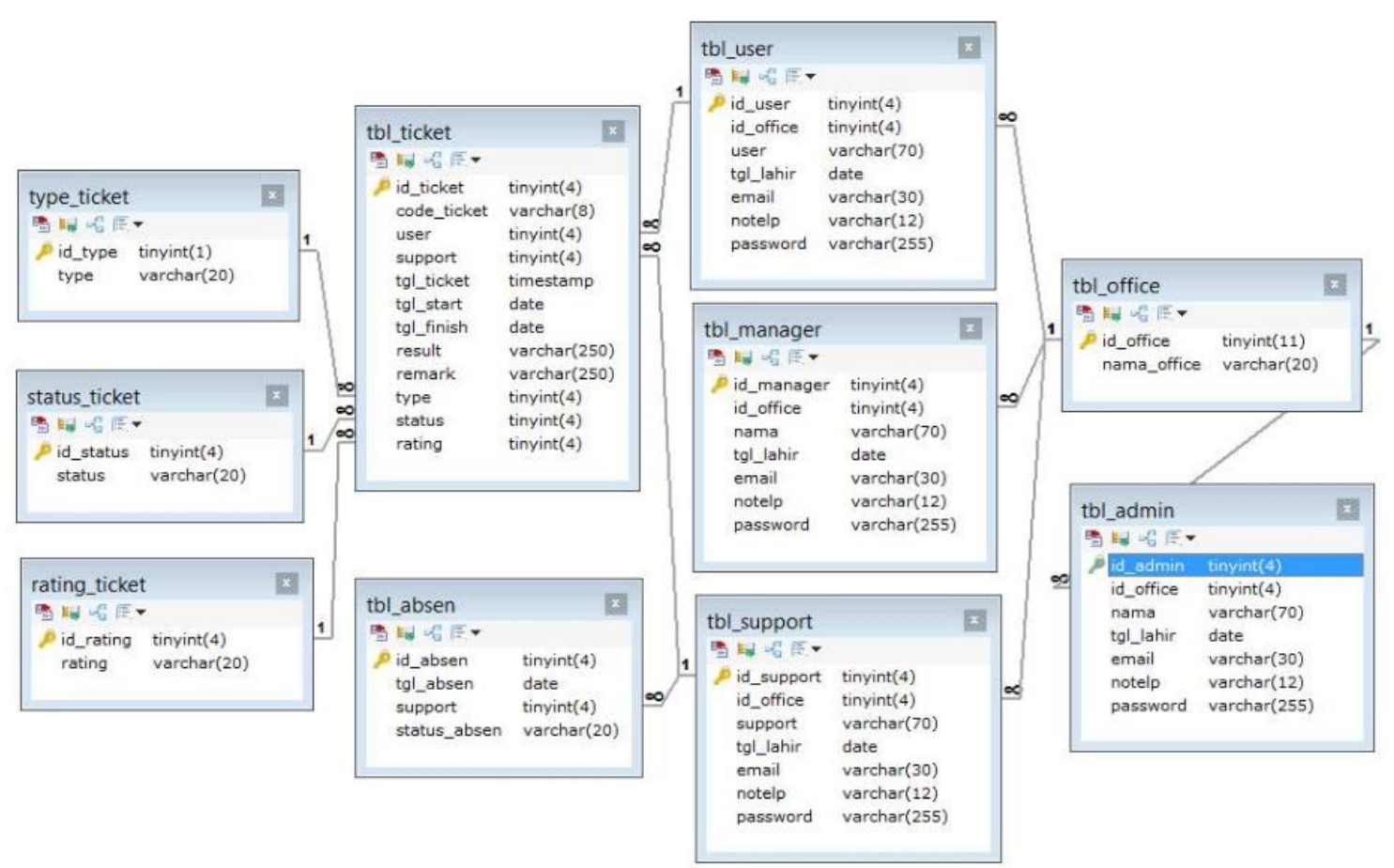

Gambar 3. ERD

\section{Kesimpulan}

Berdasarkan hasil penelitian yang sudah dilakukan, maka dapat diambil beberapa kesimpulan yaitu Dalam mengevaluasi penilaian kinerja karyawan, pihak Manager dan Admin tidak perlu menghitung secara manual, dengan mengumpulkan data absen, rating dan nilai poin tiket karyawan. Maka perhitungan nilai karyawan sudah dapat otomatis dilakukan oleh aplikasi. Aplikasi monitoring dan evaluasi pekerjaan ini dapat digunakan untuk menampung data keluhan dan permasalahan audience (user penggunakan perangkat komputer) yang dapat langsung ditangani. Algoritma Hungarian yang di gunakan juga dapat mengalokasikan pekerjaan yang sudah di request oleh user.

\section{Terima Kasih}

Terima kasih kepada Universitas Mercu Buana dan Divisi IT PT Akulaku Silvrr yang telah memberikan kesempatan dalam melaksanakan kegiatan penelitian dan semua pihak yang telah membantu atas penelitian ini. 


\section{Daftar Pustaka}

[1] A. G. Anto, H. Mustafidah, and A. Suyadi, "Sistem Pendukung Keputusan Penilaian Kinerja Karyawan Menggunakan Metode SAW,” Juita, vol. III, no. 4, pp. 193-200, 2015.

[2] A. Mia and A. Seno, "Pengaruh Lingkungan Kerja dan Insentif terhadap Produktivitas Kerja Karyawan pada Pabrik Kelapa Sawit PT. Perkebunan Nusantara V Sei Rokan," Jom Fisip, vol. 3, no. 1, pp. 1-10, 2016.

[3] A. P. Windarto, "Penilaian Prestasi Kerja Karyawan PTPN III Pematangsiantar Dengan Metode Simple Additive Weighting (SAW)," Jurasik (Jurnal Ris. Sist. Inf. dan Tek. Inform., vol. 2, no. 1, p. 84, 2017.

[4] O. C. Oloke, A. S. Oni, D. O. Babalola, and R. A. Ojelabi, "Incentive Package, Employee's Productivity and Performance of Real Estate Firms in Nigeria," Eur. Sci. Journal, ESJ, vol. 13, no. 11, p. 246, 2017.

[5] N. Marpaung, "Penerapan Metode Simple Additive Weighting Pada Sistem Pendukung Keputusan Untuk Menentukan Kenaikan Gaji Karyawan,” Jurteksi, vol. 4, no. 2, pp. 171-178, 2018.

[6] W. Gunawan, "ERP System As A Inventory Control And Waste Elimination (Pt Vif Case Study)," Int. J. Comput. Trends Technol., vol. 67, no. 7, pp. 8-13, 2019.

[7] R. R. Hidayat and D. Jatikusumo, "Monitoring Sistem Berbasis Web Keamanan Transaksi Pengiriman Uang Pada Penyelenggara Transfer Dana Dengan Menggunakan Peraturan Bank Indonesia Anti Pencucian Uang \& Pencegahan Pendanaan Terorisme," Petir, vol. 12, no. 1, pp. 8192, 2019.

[8] M. Purwokerto et al., "Sistem Pendukung Keputusan Penilaian Kinerja Karyawan Menggunakan Metode SAW ( Simple Additive Weighting) di Universitas Muhammadiyah Purwokerto ( Decision Support System of Human Resources Performance Assessment Using SAW ( Simple Additive Weighting ) M," JUITA J. Inform., vol. III, no. November, pp. 193-200, 2015.

[9] S. Bariasti and A. Lestari, "Penyelesaian Masalah Penugasan Menggunakan Metode Hungarian dan Pinalti," Sains Mat. dan Stat., vol. 3, no. 1, p. 1, 2017.

[10] T. S. Santoso and A. Saikhu, "Desain dan Analisis Algoritma Modifikasi Hungarian untuk Permasalahan Penugasan Dinamis Pada Studi Kasus Permasalahan SPOJ Klasik 12749," vol. 2, no. $1,2014$.

[11] R. T. Subagio and M. T. Abdullah, "Penerapan Metode SAW ( Simple Additive Weighting ) dalam Sistem Pendukung Keputusan untuk Menentukan Penerima Beasiswa Application of SAW ( Simple Additive Weighting ) Method in System Decision Supporters to Determine Scholarship Recipients," STMIK Catur Insa. Cendika, pp. 61-68, 2016.

[12] A. Setiadi, Y. Yunita, and A. R. Ningsih, "Penerapan Metode Simple Additive Weighting(SAW) Untuk Pemilihan Siswa Terbaik," J. Sisfokom (Sistem Inf. dan Komputer), vol. 7, no. 2, p. 104, 2018.

[13] A. Suryana, E. Yulianto, and K. D. Pratama, "Perancangan Sistem Pendukung Keputusan Penilaian Prestasi Pegawai Menggunakan Metode Saw, Ahp, Dan Topsis," J. Ilm. Teknol. Inf. Terap., vol. 3, no. 2, pp. 130-139, 2017.

[14] T. A. Kurniawan, "Pemodelan Use Case (UML): Evaluasi Terhadap beberapa Kesalahan dalam Praktik," J. Teknol. Inf. dan Ilmu Komput., vol. 5, no. 1, p. 77, 2018.

[15] D. Puspitasari, "Sistem Informasi Perpustakaan Sekolah Berbasis Web," J. Pilar Nusa Mandiri Vol. XII, vol. 12, no. 2, pp. 227-240, 2016. 